\title{
Letter to the Editor: Child Torture as a Form of Child Abuse
}

\author{
Randell Curtis Alexander ${ }^{1} \cdot$ Emmanuel Peña $^{1}$ (D)
}

Published online: 29 July 2016

(C) Springer International Publishing 2016

\section{Letter to the Editor}

Regarding Child Torture: A Form of Child Abuse by Knox et al. (2014)

We commend Dr. Knox and her colleagues for their excellent article describing child torture and proposing a definition for it (Knox et al., 2014). Unfortunately, those involved in child abuse probably have all seen such cases, indicating that this is not as unusual as could be hoped. The authors' proposed definition in Table 4, encompasses most of the elements to be considered in such cases. However, we have two suggestions.

First, the definition is restricted to physical torture and might be labeled as such. Despite the apparent repeated sexual trauma for the child in their detailed case description, this is not addressed in their definition of child torture. The consequences of sadistic sexual abuses can be similarly psychologically traumatic, may have different dynamics, and thus warrant their own definition.

The second suggestion is that they define one element of (physical) torture as resulting in "permanent bodily dysfunction." This seems to be an awkward usage and might be better phrased as "prolonged bodily dysfunction." In rare instances it might be argued that you would have to wait a lifetime to see if it is "permanent." More in keeping with the spirit of the rest of the article and its examples, "prolonged" would be a more functional definition that could be used by practitioners and better understood by the legal system as they hope.

\section{References}

Knox, B. L., Starling, S. P., Feldman, K. W., Kellogg, N. D., Fraiser, L. D., \& Tiapula, S. L. (2014). Child torture as a form of child abuse. Journal of Child \& Adolescent Trauma, 7, 37-49. doi:10.1007/ s40653-014-0009-9.

Emmanuel Peña

emmanuel.pena@jax.ufl.edu

Randell Curtis Alexander

ralexander@abusenet.org

1 Division of Child Protection and Forensic Pediatrics, University of Florida-Jacksonville, Jacksonville, FL, USA 